\title{
Estimating malaria transmission in Sarangani Province, the Philippines using serological markers of infection
}

\author{
Mary Grace Dacuma ${ }^{1,2^{*}}$, Judeline Dimalibot ${ }^{2}$, Federico Yadao ${ }^{3}$, Antonio Yasaña ${ }^{3}$, Ernesto Bona ${ }^{4}$, Walter Notario ${ }^{5}$, \\ Rachel Hallett ${ }^{1}$
}

From Challenges in malaria research

Basel, Switzerland. 10-12 October 2012

\section{Background}

The Philippines is among the 39 countries aiming for malaria elimination. The major challenge is finding residual transmission foci in difficult to access villages of Southern Mindanao, Philippines. The sensitivity of microscopy to detect asymptomatic infections declines with decreasing malaria prevalence. The aim of this project is to use antibody markers of $P$. falciparum and $P$. vivax infection to locate residual transmission foci and to determine effects of control measures in Sarangani Province, the Philippines.

\section{Methods}

Filter paper blood spots from 907 participants (aged 1 86 yrs) were collected in a cross-sectional survey from nine villages in Sarangani Province, Philippines between June - August 2010. Sera extracted blood spots were tested for presence of antibodies to P. falciparum and $P$. vivax apical membrane antigen 1 (AMA1) and merozoite surface protein $1\left(\mathrm{MSP}_{19}\right)$ using indirect ELISA [1].The mixture model was used to define the cut off value for presence or absence of antibody to the antigen tested. The dichotomized sera were fitted into reversible prevalence catalytic models using maximum likelihood estimation to generate age-specific seroprevalence curve [2]. Statistical analyses were done using the STATA ${ }^{\circledR}$ v12 software (Stata Corp., Texas).

\section{Results}

The age-specific seroprevalence curves for Pf-AMA1 and Pf-MSP $1_{19}$ showed that the force of P. falciparum

'London School of Hygiene and Tropical Medicine, London, WC1E 7HT, UK Full list of author information is available at the end of the article infection $(\lambda)$ per year in Sarangani Province was 0.005 (95\% CI: $0.003-0.009)$ and 0.03 (95\% CI: $0.02-0.05$ ), respectively. This result was supported by records of annual parasite incidence (API per 1,000) in Sarangani that decreased from 3.49 in 2005 to 0.57 in 2009 . There was strong evidence $(\mathrm{P}<0.001)$ that the difference in exposure to $P$. falciparum varies between the nine villages. The age-specific seroprevalence curve to PvAMAI showed that in 2010 the force of $P$. vivax infection $(\lambda)$ per year was 0.02 (95\% CI: $0.01-0.04)$, which reflected a decline in transmission as observed in seroprevalence curves to Pf-AMA1 and Pf-MSP ${ }_{19}$. The force of infection using $\mathrm{Pv}-\mathrm{MSP}_{19}$ was not calculated because its seroprevalence curve showed a horizontal line (probability positive of 0.1 ). This suggested that either $P$. vivax epidemic occurred in the province where individuals exposed developed antibodies to $P$. vivax at one point in time as observed in Vanuatu [3]; or a relapse of $P$. vivax infections due to activation of liver hypnozoites. There was strong evidence $(\mathrm{P}<0.001)$ that $P$. vivax transmission differed between the villages surveyed.

\section{Conclusion}

The results show that $P$. falciparum and P.vivax transmission continue at very low levels in Sarangani Province, the Philippines despite strengthened control efforts. It is recommended that elimination efforts are intensified in villages where antibody prevalence to $P$. falciparum and $P$. vivax infections is higher relative to the nine villages surveyed.

\footnotetext{
Author details

'London School of Hygiene and Tropical Medicine, London, WC1E 7HT, UK. ${ }^{2}$ University of the Philippines Los Baños, Laguna, 4031, Philippines.
} 
${ }^{3}$ Provincial Health Office, Alabel, Sarangani Province, 9501, Philippines.

${ }^{4}$ Department of Health Region XII, Alabel, Sarangani Province, 9501,

Philippines. ${ }^{5}$ Pilipinas Shell Foundation, Alabel, Sarangani Province, 9501,

Philippines.

Published: 15 October 2012

\section{References}

1. Drakeley CJ, Corran PH, Coleman PG: Estimating medium-and long-term trends in malaria transmission by using serological markers of malaria exposure. PNAS 2005, 102(14):5108-5113.

2. Corran P, Coleman P, Riley E: Serology: a robust indicator of malaria transmission intensity? Trends Parasitol 2007, 23(12):575-582.

3. Cook J, Reid H, lavro J: Using serological measures to monitor changes in malaria transmission in Vanuatu. Malaria J 2010, 9:169.

doi:10.1186/1475-2875-11-S1-P20

Cite this article as: Dacuma et al.: Estimating malaria transmission in

Sarangani Province, the Philippines using serological markers of

infection. Malaria Journal 2012 11(Suppl 1):P20.

\section{Submit your next manuscript to BioMed Central} and take full advantage of:

- Convenient online submission

- Thorough peer review

- No space constraints or color figure charges

- Immediate publication on acceptance

- Inclusion in PubMed, CAS, Scopus and Google Scholar

- Research which is freely available for redistribution

Submit your manuscript at www.biomedcentral.com/submit 